\title{
SOLO KONDOMINIUM, HOTEL, AND SHOPING MALL BERPENDEKATAN ARCHITECTURE SUSTAINABLE DESIGN
}

\author{
Maria Rina Alfie Oktavia \\ Program Studi Arsitektur, Fakultas Teknik, Universitas Tunas Pembangunan \\ Email: Mariarina10@gmail.com \\ Indro Sulistyanto \\ Dosen Arsitektur, Fakultas Teknik, Universitas Tunas Pembangunan \\ Email: indrosulistyanto@yahoo.com \\ Ismadi \\ Dosen Arsitektur, Fakultas Teknik, Universitas Tunas Pembangunan \\ Email: ismadi.ir@gmail.com
}

\begin{abstract}
Abstrak
Kota Surakarta juga disebut Solo atau Sala melengkapi fungsi kota yaitu pengembangan sektor-sektor : Pariwisata, pendidikan, industri, perdagangan, budaya dan olahraga. Permasalahan yang timbul baik dari tuntutan manusia,kebutuhan akses cepat menuju area perkantoran, gaya hidup, pengaruh tingkat kemacetan lalu lintas ekonomi maupun tuntutan lahan yang tersedia maka keberadaan Solo Kondominium, Hotel and Shopping Mall merupakan salah satu alternatif pilihan fasilitas yang cukup untuk memenuhi tuntutan kebutuhan saat ini dan dapat sebagai investasi dimasa mendatang sesuai kualitas penghuninya. Dalam hal ini baik kualitas fisik bangunan yang menarik, letak yang strategis, dan fasilitas penunjang yang lengkap serta kualitas non fisik yang berupa tingkat privasi yang tinggi, rasa aman, suasanya yang menyenangkan dan nyaman. Konsep dasar perencanaan dan perancangan yang digunakan yaitu Sustainable Design yang berkaitan pada ketiga fungsi bangunan Solo Kondominium, Hotel and Shopping Mall. Dimana konsep yang digunakan dalam memanfaatkan potensi-potensi yang ada pada lokasi perancangan sehingga terjadi hubungan timbal balik yang saling mendukung antara objek perancangan dengan lingkungan sekitar, Karena definisi dari Sustainable Design sendiri adalah menciptakan dan mengoperasikan suatu lingkungan buatan (build environment) yang sehat berdasarkan kepada efisiensi sumber daya dan design ekologi. Pendekatan dengan konsep sustainable design akan diterapkan pada perencanaan dan perancangan Solo Kondominium, Hotel and Shopping Mall dalam rangka menciptakan dan mengoperasikan suatu lingkungan buatan (build environment) yang sehat berdasarkan kepada efisiensi sumber daya dan design ekologi. Guna meminimalisir kerusakan lingkungan karena dampak global warming.
\end{abstract}

\section{Kata kunci: Solo Kondominium, Hotel, And Shoping Mall}

Abstract
The city of Surakarta also called Solo or Sala complements the functions of the city,
namely the development of sectors: tourism, education, industry, trade, culture and
sports. Problems arising both from human demands, the need for quick access to
office areas, lifestyle, the influence of the level of traffic congestion, the economy, and
the demands of land available, the existence of Solo Condominium, Hotels and


Shoping Mall, is one alternative choice of adequate facilities to meet the demands of current needs and be as an investment in the future according to the quality of its occupants. In this case both the physical quality of the building is attractive, strategic location, and complete supporting facilities and non-physical quality in the form of high levels of privacy, security pleasant and comfortable. The basic concept of planning and design used is Sustainable Design which relates to the three building functions of Solo Condominium, Hotel and Shoping Mall. Where the concept is used in utilizing the potentials that exist in the design location so that mutual relations occur between the design objects with the surrounding environment, Because the definition of Sustainable Design itself is to create and operate a healthy build environment based on resource efficiency and ecological design. The approach to the concept of sustainable design will be applied to the planning and design of the Solo Condominium, Hotel and Shoping Mall in order to create and operate a healthy build environment based on resource efficiency and ecological design. To minimize environmental damage due to the impact of global warming.

\section{Keywords: Solo Kondominium, Hotel, And Shoping Mall}

\section{PENDAHULUAN}

Kota Surakarta juga disebut Solo adalah wilayah otonom dengan status kota di bawah Provinsi Jawa Tengah, Indonesia, penyebutan nama Solo dan Surakarta seperti ada pembagiannya sendiri-sendiri. Nama Solo biasanya mengarah pada nama atau wilayah yang ada di dalamnya.Kota Surakarta melengkapi fungsi kota yaitu pengembangan sektor-sektor : Pariwisata, pendidikan, industri, perdagangan, budaya dan olahraga. Perkembangan wilayah pada bidang pariwisata mendorong pembangunan kota untuk memberikan fasilitas hunian yang lebih memadai untuk mewadahi kegiatan-kegiatan yang muncul.Wajah kota Surakarta beberapa tahun ini menunjukkan perubahan sangat pesat. Seiring dengan banyaknya bangunan modern yang ada di kota Surakarta. Hal ini didukung dengan beroperasinya sejumlah pusat perbelanjaan dan perkantoran di pusat kota dan di lokasi lain di sekitar kota Surakarta. Kawasan perumahan elite maupun sederhana menjamur di kota Surakarta dan sekitarnya. Bangunan kontemporer atau kekinian merupakan hasil dari perubahan pola pikir, pola hidup dan juga budaya masyarakat dengan tumbuhnya dinamika dan tuntutan masyarakat modern baik kualitas maupun kuantitas dan juga menempatkan masyarakat kota Surakarta dalam kehidupan di zamannya. Hal ini diperkuat dengan adanya pembangunan tiga apartemen modern yang berada di pusat kota Surakarta dan juga bangunan-bangunan modern lainnya yang semakin banyak jumlahnya. Jadi persepsi masyarakat akan berkembangnya Surakarta menjadi Megapolis akan menjadi kenyataan.

Permasalahan yang timbul baik dari tuntutan manusia,kebutuhan akses cepat menuju area perkantoran, gaya hidup, pengaruh tingkat kemacetan lalu lintas,ekonomi,maupun tuntutan lahan yang tersedia,maka keberadaan Solo Kondominium, Hotel and Shopping Mall, merupakan salah satu alternatif pilihan fasilitas yang cukup untuk memenuhi tuntutan kebutuhan saat ini dan dapat sebagai investasi dimasa mendatang sesuai kualitas penghuninya .Dalam hal ini baik kualitas fisik bangunan yang menarik, letak yang staregis, dan fasilitas penunjang yang lengkap serta kualitas non fisik yang berupa tingkat privasi yang tinggi, rasa aman, suasanya yang menyenangkan dan nyaman,dsb.

Kondominium dari segi fungsinya sama seperti rumah susun tetapi lebih baik dari segi fasilitasnya dan cocok untuk kalangan pada high end. Kondominium didukung dengan fasilitasfasilitas penunjang seperti kolam renang café dan restaurant, mini shop, laundry service, fitness center, sistem keamanan 24 jam, dan lain-lain. Kondominium dinilai hunian yang praktis untuk zaman modern seperti sekarang, lokasi yang berada pada pusat kota memudahkan untuk melakukan aktifitas. Selain itu kondominium menghemat lahan untuk pembuatan hunian. 
Hotel merupakan bangunan berkamar banyak yang disewakan sebagai tempat untuk menginap dan tempat makan orang yang sedang dalam perjalanan, selain itu dapat diartikan sebagai bentuk akomodasi yang dikelola secara komersial yang disediakan bagi setiap orang untuk memperoleh pelayanan, penginapan, makan, dan minum. Sedangkan berdasarkan pendapat lain hotel adalah sarana tempat tinggal umum untuk wisatawan dengan memberikan pelayanan jasa kamar, penyedia makanan dan minuman serta akomodasi dengan syarat pembayaran. Sektor pariwisata dikota surakarta mengalami peningkatan kebutuhan kamar untuk membantu para turis atau pendatang singgah dan bertempat tinggal dengan fasilitas hotel yang berada di tengah kota dirasa masih kurang cukup,hotel kota dapat menjadi pilihan bagi para pendatang sebagai tempat untuk tempat tinggal sementara .

Shoping Mall adalah tempat orang berjalan dengan santai dengan sebelah kanan dan kirinya terdapat took-toko yang mudah dicapai dari tempat parkir. Pada awalnya, Shoping mall merupakan evolusi dari pasar tradisional sebagai tempat untuk berdagang. Namun, dengan seiringnya perkembangan zaman yang berbanding dengan peningkatan permintaan dan peningkatan kualitas barang yang dijual maka ruang untuk membeli dan menjual barang ini ditingkatkan kualitasnya dengan penerapan konsep baru dan penambahan fasilitas penunjang. Fasilitas penunjang diantaranya bioskop, area bermain anak, area pertunjukan, taman-taman tematik, dan lain sebagainya. Selain karena permintaan, penambahan fasilitas ini juga didasari pada perubahan gaya hidup manusia yang telah berubah dimana saat ini tujuan pengunjung berkunjung ke pusat perbelanjaan bukanlah untuk berbelanja, melainkan untuk berekreasi.

Konsep dasar perencanaan dan perancangan yang digunakan yaitu Sustainable Design yang berkaitan pada ketiga fungsi bangunan Solo Kondominium, Hotel and Shoping Mall. Dimana konsep yang digunakan dalam memanfaatkan potensi-potensi yang ada pada lokasi perancangan sehingga terjadi hubungan timbal balik yang saling mendukung antara objek perancangan dengan lingkungan sekitar, Karena definisi dari Sustainable Design sendiri adalah menciptakan dan mengoperasikan suatu lingkungan buatan (build environment) yang sehat berdasarkan kepada efisiensi sumber daya dan design ekologi.

Berdasarkan uraian diatas dapat disimpulkan bahwa di kota Surakarta, dibutuhkan sebuah Solo Kondominium, Hotel and Shoping Mall. Perencanaan dan perancangan ini diharapkan mampu mengakomodasi kebutuhan ekonomi, kebutuhan tempat tinggal khususnya bagi masyarakat kalangan menengah ke atas, bekerja disekitar kawasan ,maupun masyarakat umum dan pendatang. Pendekatan dengan konsep sustainable design akan diterapkan pada perencanaan dan perancangan Solo Kondominium, Hotel and Shoping Mall dalam rangka menciptakan dan mengoperasikan suatu lingkungan buatan (build environment) yang sehat berdasarkan kepada efisiensi sumber daya dan design ekologi. Guna meminimalisisr kerusakan lingkungan karena dampak global warming.

\section{PERMASALAHAN}

Bagaimana merencanakan dan merancang kesatuan penampilan (Unity) pada ke tiga fungsi Solo Kondominium, Hotel and Shopping Mall?

\section{LANDASAN TEORI}

Pengertian-pengertian dari spesifikasi kata-kata penyusun kalimat judul yang berlaku sebagaimana yang akan di terangkan seperti di bawah ini.

a. Kondominium

Menurut Gorlier (1975) "The condo is A building consisting of 3 or more dwellings which is a shared life and each unit can be used separately". Yaitu Kondominium merupakan sebuah bangunan yang terdiri dari 3 atau lebih hunian yang merupakan suatu kehidupan bersama dan masing-masing unit dapat digunakan secara terpisah .

b. Hotel

Yang dimaksud dengan hotel adalah bangunan berkamar banyak yang disewakan sebagai tempat untuk menginap dan tempat makan orang yang sedang dalam perjalanan, selain itu dapat diartikan sebagai bentuk akomodasi yang dikelola secara komersial yang disediakan bagi setiap orang untuk memperoleh pelayanan, penginapan, makan, dan minuman serta fasilitas 
lainnya untuk tamu-tamu yang datang, yang mana seluruh fasilitasnya di peruntukan bagi seluruh masyarakat umum yang datang untuk menginap.

\section{c. Shopping Mall}

Menurut Chiara and Callender (1969) "Shopping mall is a complex retailer shop of its supporting facilities which is planned as a unit to provide maximum comfort for visitors and maximum promotion of goods sold" .Shopping mall adalah suatu kompleks toko pengecer dari fasilitas pendukungnya yang direncanakan sebagai suatu kesatuan untuk memberikan kenyamanan yang maksimal bagi pengunjung dan promosi maksimal bagi barang-barang yang dijualKarena bentuk arsitektur bangunannya yang melebar (luas), umumnya sebuah mall memiliki tinggi tiga lantai.

\section{METODE PENELITIAN}

Metode yang digunakan adalah sebagai berikut:

\section{Lokasi}

Memberikan gambaran tentang lokasi Kota Surakarta sebagai dasar point untuk mendapatkan latar belakang keberadaan Solo Kondominium,Hotel and Shoping Mall.

2.

Sumber data yang akan dimanfaatkan meliputi:

- $\quad$ Narasumber

- $\quad$ Tempat/ Lokasi

- Dokumen

- Internet

3. Tahap Pengumpulan

\section{Data}

a. Studi literature

Yang terdiri dari studi literature melalui media cetak (buku, majalah, surat kabar, tesis, laporan penelitian), media elektronik (internet, televisi) dan lain-lain.

b. Observasi Langsung

Menggali data melalui observasi lapangan, survey lokasi secara langsung sehingga dapat memperoleh data lapangan secara real/ nyata.

c. Wawancara

Melakukan narasumber berkompeten dibidang yang berhubungan dengan objek perancangan.

d. Dokumentasi

Hasil dari foto-foto atau gambar yang berkaitan dengan survey lapangan pada berbagai bangunan Kondominium, Hotel and Shopping Mall sebagai pendukung data lapangan.

e. Analisis Data

Melalui tahap-tahap pendekatan:

- Mengumpulkan data yang relevan sebagai awal pembahasan dengan pengamatan secara langsung di lapangan dan pengumpulan literature.

- Mengungkapkan permasalahan perencanaan dan perancangan dari data-data yang ada.

- Menentukan tujuan perencanaan dan perancangan.

- Menyusun dasar-dasar teori dan aspek-aspek yang mendukung.

- Menyusun konsep kegiatan.

- Menyusun konsep perancangan serta mengambil keputusan/ penarikan kesimpulan.

\section{PEMBAHASAN}

A. Lokasi dan Tapak

Perencanaan dan perancangan Solo Kondominium Hotel and Shopping Mall agar tercipta dengan baik serta sesuai dengan tujuan dan sasaran, maka dari hasil analisa lokasi yang terpilih yaitu pada SWP VI Kota Surakarta.

Dasar pertimbangan pemilihan lokasi dan Tapak yaitu sebagai berikut:

1. Peraturan Tata Guna Lahan

2. Kondisi Lingkungan

3. Sarana Utilitas

Tersedia sarana utilitas kota, seperti jaringan listrik, air bersih, drainase dan jaringan telekomunikasi.

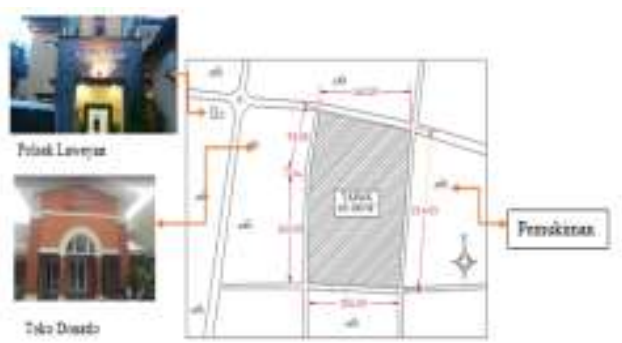

Gambar 1 Tapak Solo Kondominium,Hotel, And Shopping Mall 
(Sumber: Data Pribadi)

Sesuai dengan hasil pembobotan Alternatif terpilih berada di Selatan J1. Dr.Radjiman, Panularan, Laweyan, Kota Surakarta, Jawa Tengah. Luas tapak yaitu $40.100 \mathrm{~m} 2$ cukup memadai untuk dibangunnya Solo Kondominium,Hotel and Shopping Mall.

Dengan batas-batas wilayah sebagai berikut:

1.Batas Utara : Jalan satu arah,Jln.Radjiman

2.Batas Timur : Permukiman

3. Batas Selatan : Jalan Permukiman

4. Batas Barat : Jln.Rojo Manggolo

B. Pengolahan Tapak

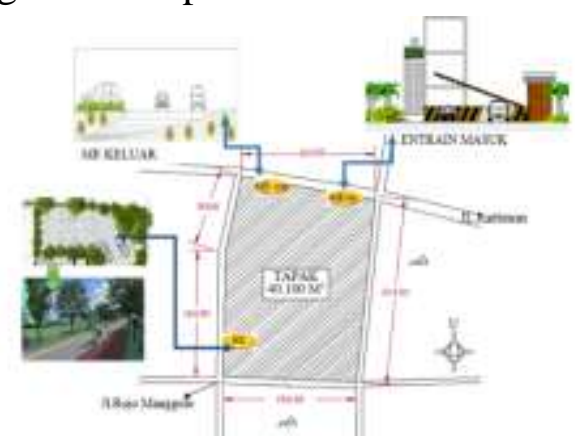

Gambar 2 Pengolahan Tapak Solo Kondominium,Hotel, And Shopping Mall

(Sumber: Data Pribadi)

Keterangan:

- Jalan Radjiman dilalui kendaraan roda empat, mobil pribadi, kendaraan umum, motor, sepeda, dan pejalan kaki dari arah timur ke utara.

- Jalan Rojo Manggolo dapat dilalui kendaraan mobil pribadi, motor, sepeda, dan pejalan kaki.

1) Untuk memenuhi kriteria lokasi Main Entrace terutama pada Jl Radjiman. Maka solusi yang direncanakan sebagai berikut:

a) Menbuat Sclupture atau papan nama pada Solo Kondominium, Hotel and Shopping Mall, agar lebih mudah dikenali dan pengunjung tidak bingung ketika memasuki bangunan komersil.

b) Membuat pelebaran jalan sehingga mudah dicapai dan juga aman dalam pencapaian.

2) Untuk memenuhi kriteria Side Entrance ( SE) terutama pada Jl. Rojo Monggolo. Maka solusi yang digunakan sebagai berikut: a) $\mathrm{SE}$ dapat mendukung kegiatan penghuni,pengelola, karyawan dan juga kegiatan servis.

b) Letaknya mudah dicapai dan aman dalam pencapaian.

c) Pendestrian sebagai area pejalan kaki.

d) Tidak menyebabkan kemacetan.

e) Tidak mengganggu kegiatan utama pada bangunan komersil.

C. Orientasi Bangunan

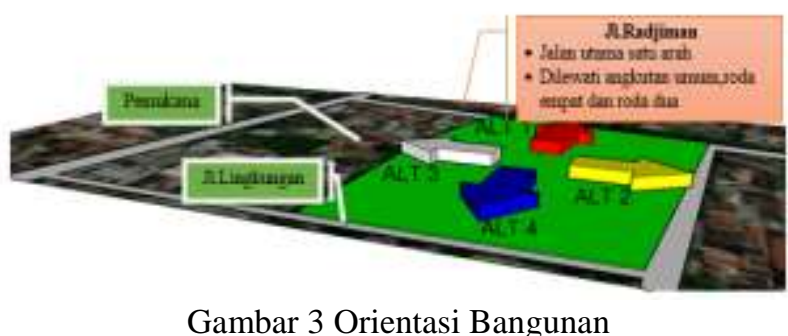

(Sumber: Data Pribadi)

Keterangan:

-Alternatif 1: menghadap ke arah timur, jalan lingkungan dan pemukiman.

-Alternatif 2: menghadap ke arah utara, jalan Radjiman sebagai jalan utama akses ke tapak.

-Alternatif 3: menghadap ke arah pemukiman dan jalan rojo monggolo.

-Alternatif 4: menghadap ke arah jalan lingkungan dan pemukiman.

Letak arah hadap bangunan yaitu menghadap ke Jalan Radjiman, sedangkan arah hadap sekunder yaitu menghadap ke jalan Rojo Monggolo.

D. Kebisingan

Kebisingan berasal dari aktifitas pemukiman sekitar, aktifitas kendaraan maupun segala aktifitas yang timbul menggangu kenyamanan pengguna Kondominium,Hotel and Shopping Mall. 


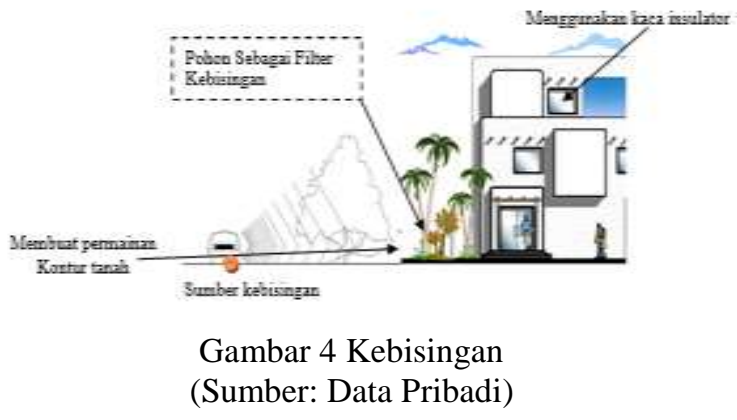

Keterangan:

- Pepohonan yang diletakkan pada sisi luar tapak berbatasan dengan jalan, sebagai barier untuk memfilter bising dari kendaraan.

- Bagian dalam ditanami vegetasi sebagai peredam

- Area yang memiliki potensi bising cukup tinggi digunakan sebagai area parkir atau taman.

- Masa bangunan diletakkan pada area tingkat kebisingan sedang dan rendah/ jauh dari kebisingan yang berasal dari luar tapak.

E. Matahari

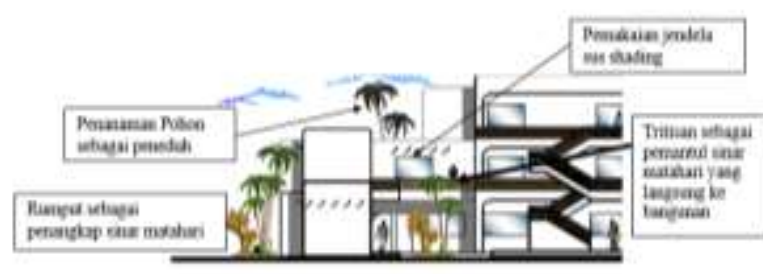

Gambar 5 Matahari

(Sumber: Data Pribadi)

- Masa yang ideal bukaan menghadap ke arah utara dan arah timur untuk menghindari panas matahari yang kurang baik.

- Pemasangan grass block atau rumput sebagi penyerap sinar matahari .

- Penanaman pohon yang cukup rindang dan tinggi sebagai filter sinar matahari dan dapat menyejukan lingkungan sekitar tapak.

- Pemakaian Sun Shading pada jendela sehingga cahaya yang masuk pada ruangan tidak berlebih dan mengganggu aktifitas.

- Tritisan sebagai penghalang sinar matahari yang masuk pada ruangan sehingga cahaya yang masuk pada ruangan dapat terkontrol.

\section{F. Titik Tangkap}

Titik tangkap didukung oleh letak tapak yang strategis yaitu berada pada Jalan Radjiman.Tujuan analisis titik tangkap adalah untuk menentukan daerah titik tangkap terbesar sebagai perletakan poin of interest pada tapak yang mendukung daya tarik bagi pengamat dan terpilihlah point interest menghadap pada jalan Dr.Radjiman.

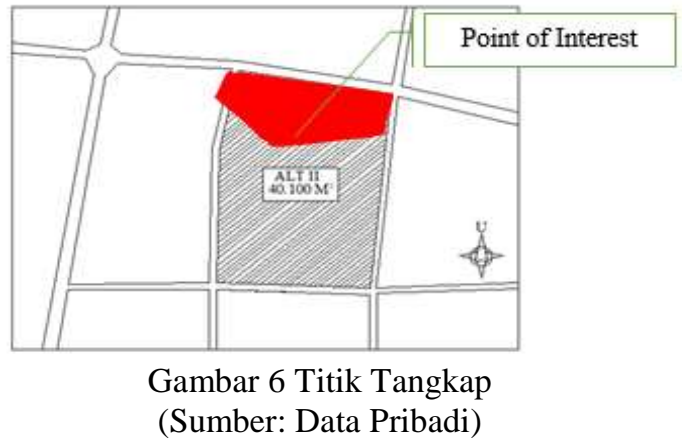

Berdasarkan hasil analisis diatas, warna merah pada tapak yaitu area yang paling banyak dipandang dari jalan raya ataupun pejalan kaki. Oleh karena itu diarea tersebut sebagai area point of interes pada suatu bangunan.

\section{G. Rekapitulasi Data}

\begin{tabular}{|c|c|c|}
\hline Kelompok Kegiatan & Besaran Ruang+flow & $\begin{array}{c}\text { Besaran } \\
\text { Ruang }\end{array}$ \\
\hline Kondominium & $19.715 \mathrm{~m}^{2}+$ flow $30 \%$ & $25.629 \mathrm{~m}^{2}$ \\
\hline Hotel & $17.346 \mathrm{~m}^{2}$ +flow $30 \%$ & $22.549 \mathrm{~m}^{2}$ \\
\hline Shopping Mall & $25.714 \mathrm{~m}^{2}+$ flow $30 \%$ & $33.428 \mathrm{~m}^{2}$ \\
\hline Servis & $237 \mathrm{~m}^{2}+$ flow $20 \%$ & $284 \mathrm{~m}^{2}$ \\
\hline \multicolumn{2}{|c|}{ Total } & $81.890 \mathrm{~m}^{2}$ \\
\hline
\end{tabular}

Gambar 7 Rekapitulasi Data

(Sumber: Data Pribadi)

Regulasi bangunan yaitu setiap bangunan campuran diatur menurut status induknya ditambah status tambahannya yang kemudian menyesuaikan status induknya, dalam perencanaan Solo Kondominium,Hotel and Shopping Mall status induknya adalah Kondominium atau tempat tinggal yang ditambah dengan bangunan Hotel dan Shopping Mall. Tapak terletak di Jalan Radjiman yang memiliki ketentuan:

a. Ketinggian tower Kondominium = 15 lantai.

b. Ketinggian tower Hotel= 10 lantai.

c. Ketinggian Mall (podium) $=4$ lantai 


\section{H. Pola Hubungan Ruang}

\begin{tabular}{|c|c|c|c|c|c|c|}
\hline $\begin{array}{l}\text { Kelompok } \\
\text { Ruang }\end{array}$ & Auntin & Visual & $\begin{array}{l}\text { Akses } \\
\text { Fisila } \\
\text { Informasd }\end{array}$ & Hubangan & Pvaghubung & $\begin{array}{l}\text { Jenis } \\
\text { Hlebangan }\end{array}$ \\
\hline \multirow[t]{2}{*}{ Koedonabuans } & 8 & $\checkmark$ & 8 & $\begin{array}{l}\text { Dengen } \\
\text { Ruang Lmem }\end{array}$ & Pintu & Tak Laggung \\
\hline & & & & & Koridor & Lanevian \\
\hline \multirow[t]{2}{*}{ Hotet } & v & v & $v$ & $\begin{array}{l}\text { Dengan } \\
\text { kelompok } \\
\text { Ruane Dmam }\end{array}$ & Pintu & Tak Lagring \\
\hline & & & & & Konder & Ialgrang \\
\hline \multirow[t]{3}{*}{ Shopping XGII } & - & - & - & $\begin{array}{l}\text { Densen } \\
\text { Kelomgok } \\
\text { suang Lhaum }\end{array}$ & Pintu & Tidar Langsang \\
\hline & & & & & Kandior & Langung \\
\hline & & & & & Kordot & Langeang \\
\hline
\end{tabular}

Gambar 9 Pola Hubungan Ruang

(Sumber: Data Pribadi)

I.

Zonasi

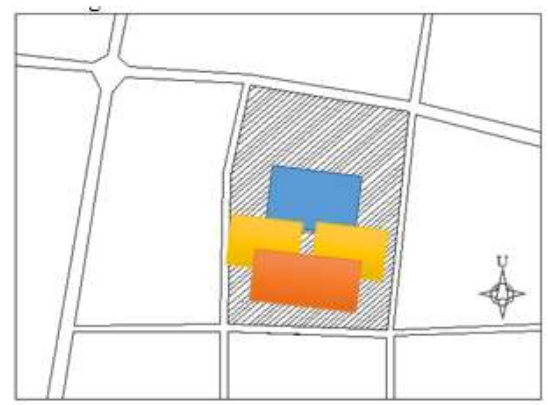

Gambar 10 Zona Horizontal

(Sumber: Data Pribadi)

\section{Keterangan:}
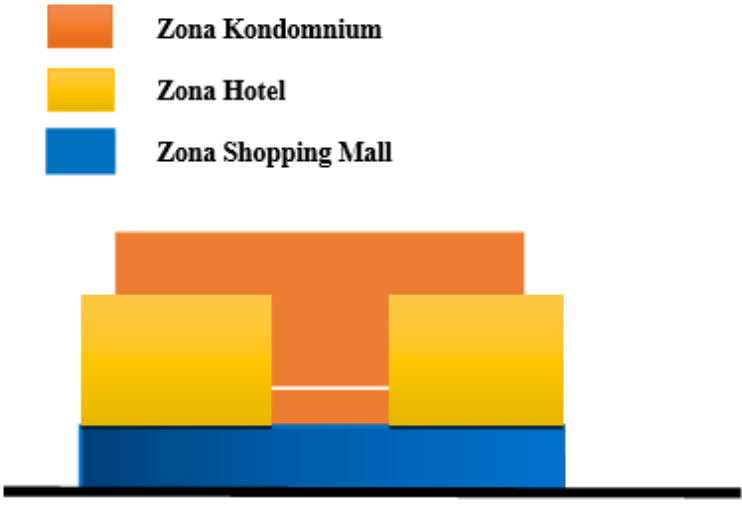

Gambar 11 Zona Vertikal (Sumber: Data Pribadi)

\section{J. Ungkapan Fisik Bangunan}

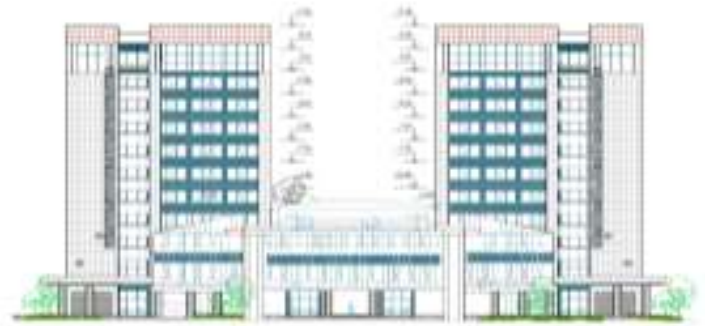

Gambar 12 Tampak Hotel
(Sumber: Data Pribadi)

Berdasarkan hasil pendekatan konsep penampilan bangunan. Pada Solo Kondominium, Hotel and Shopping Mall untuk mewujudkan unity sustainable design, menggunakan kesatuan tekstur bahan yang dominan dilanjutkan kesatuan warna dan pola sebagai fasade bangunan, komposisi bangunan yang simetris dengan menggunakan gaya Arsitektur Kontemporer .

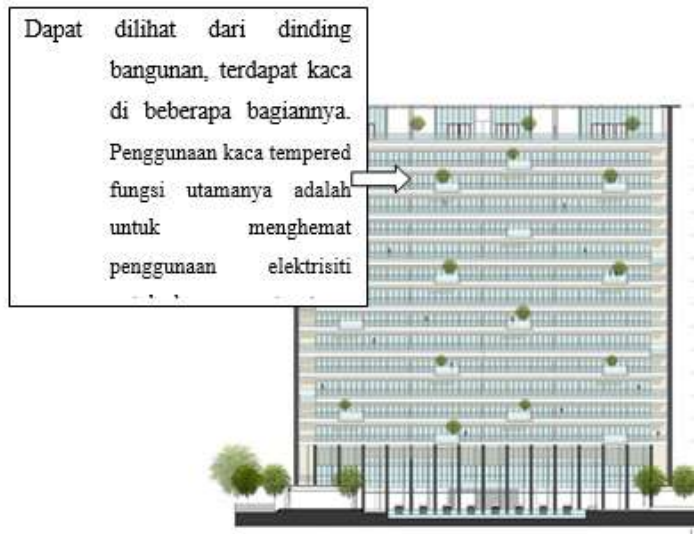

Gambar 13 Potongan Kondominium

(Sumber: Data Pribadi)

Perancangan sangat di konsepkan, tapak lingkungan wilayah yang cukup terbatas,dipadukan dengan konsep unity sustainable design dengan gaya arsitektur kontemporer bangunan ini memungkinkan terus bertahan dalam jangka panjang karena tidak merusak lingkungan sekitar yang ada. Beberapa tanaman rindang yang mengelilingi bangunan, membuat iklim udara yang sejuk dan sehat bagi kehidupan sekitar, terutama hunian di kondominium lingkungan tampak tenang, karena beberapa vegetasi dapat digunakan sebagai penahan kebisingan.

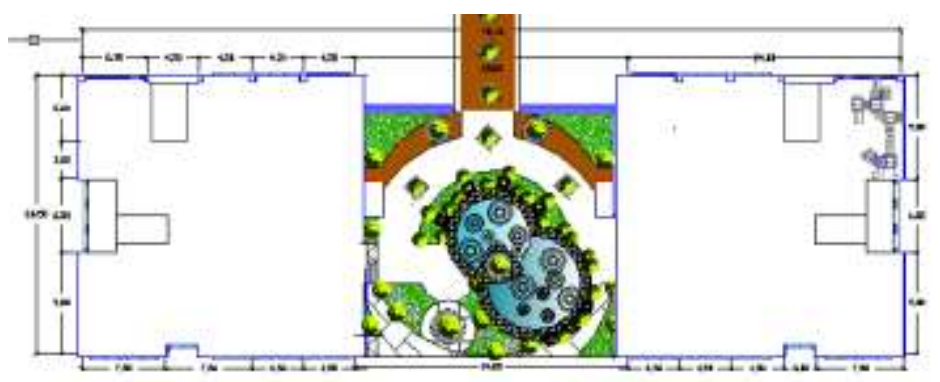

Gambar 14 Roof Top

(Sumber: Data Pribadi) 
Penggunaan green roof pada Kondominium dan Hotel, selain untuk keindahan dan agar terlihat menyatu dengan alam, juga dapat digunakan sebagai water catcher sebagi proses pendingin ruangan alami karena sinar matahari tidak diserap beton secara langsung. Ini juga menurunkan suhu panas di siang hari dan sejuk di malam hari untuk lingkungan sekitarnya. Desainnya yang melengkung digunakan agar penyerapan matahari oleh kulit bangunan dapat di minimalisasikan. Dinding bangunan curtain wall dilapisi alumunium dapat berguna untuk UV protector bangunan itu sendiri.

\section{KESIMPULAN}

Solo Kondominium, Hotel And Shopping Mall memiliki konsep kesatuan penampilan bangunan (Unity) pada ke 3 fungsi bangunan yaitu menerapkan Sustainable Design pada tiaptiap bangunan. Kesatuan penampilan bangunan dapat dilihat pada material yang dominan digunakan pada fasade bangunan seperti kaca, Alumunium, Terdapat Roof Top pada semua bangunan, Komposisi yang cenderung simetris.

Solo Kondominium, Hotel And Shopping Mall memaksimalkan penggunaan energi alami lingkungan sekitar guna mendukung penerapan konsep bangunan Sustainable Design. Design bangunan mencermikan bangunan kontemporer terlihat dari penggunaan roof garden dan material kaca, bentuk bangunan yang menyeyesuaikan fungsi bangunan.

\section{UCAPAN TERIMA KASIH}

Penulis mengucapkan terima kasih kepada:

1. Ir. Eny Krisnawati, M.Si., selaku Dekan FT UTP.

2. A.Bamban Yuuwono, ST., MT. Selaku Ketua Prodi Arsitektur FT.Teknik

3. Ir. Indro Sulistyanto, MT., selaku Dosen Pembimbing Utama.

4. Ir. Ismadi, MT., selaku Dosen Pembimbing.

5. Orang tua dan keluarga yang memberikan dukungan baik secara moral maupun materi kepada penulis.

6. Bagas Tri Hantoro.

7. Semua teman-teman Arsitektur angkatan 2015.

8. Semua pihak yang tidak dapat disebutkan satu per satu, yang telah ikut membantu secara langsung maupun tidak langsung.

\section{DAFTAR PUSTAKA}

Joseph De Chiara,Time-Saver Standards For Building Types, 1975.

Fred Lawson, Hotels, Motels dan Condominium

Design, Planning and Maintenance, 1980.

Sudarto Mangkuwerdoyo, Pengantar Industri

Akomodasi dan Perhotelan,1999.

Ernst Neufert, Data Arsitek, 1987 hal 211.

Hornbeck, James. Dormitories.New York :

McGraw-Hill Book, 1962.

De Chiara, Joseph dan Callender, John

Hancock. Time Saver Standard for Building

Types. Edisi ke-2. Singapore: McGraw Hill

Book. 1983.

de Chiara, Joseph \& Lee Koppelman, Planning Design Crietria International Council of Shopping Center, 1999.

International Council of Shopping Center, 1999

Rubeinstein, H. M., 1978. Central City Mall.

New York: A Willey Inter Sience

Publication.hlm 2-3

Hoyte CK,Clarity,bold-ness and Intimacy, 1978.

M.Suparno Sastra. Inspirasi Fasade Rumah Tinggal.

C.V Andi Offset, Yogyakarta. 2013.

DK Ching.,Architecture, Form, Space \& Order,1979.

Paola Sassi, Strategies for Sustainable

Architecture, Taylor \& Francis inc. New York, (2006).

Dinas Cipta Karya Dan Tata Ruang Pemerintah

Provinsi Jawa Tengah, 2016 